\title{
Treatment of Huntington's Disease
}

\author{
Samuel Frank
}

Published online: 24 December 2013

(C) The American Society for Experimental NeuroTherapeutics, Inc. 2013 involuntary movements, behavioral disturbance, cognitive dysfunction, and psychiatric disease. The disease is caused by a CAG (glutamine) trinucleotide expansion in exon 1 of the huntingtin $(h t t)$ gene at the location 4p16.9 [1]. The normal function of $h t t$ is not known, but it may be involved in internal cell signaling, maintenance of cyclic adenosine monophosphate response element binding protein, and preventing neuronal toxicity [2]. Early evidence suggests that the binding of the Ras homologue enriched in striatum protein to mutant $h t t$ ( $m h t t)$ may be necessary to cause cellular toxicity [3]. However, why the protein causes cellular toxicity in adulthood is not well understood. There is evidence suggesting that the interaction of the group 1 metabotropic glutamate receptors and $m h t t$ protein may be at the root of delayed onset [4].

Although there is no established treatment to delay the onset or forestall the progression of HD, symptomatic treatment of chorea based on the neurochemical pathology known may be beneficial in some individuals, as it may have a favorable effect on motor function, quality of life, and safety [5-7]. Clinicians may also consider treatment for dystonia, other movement disorders, and non-motor aspects of HD.

Pathologically, HD is associated with diffuse loss of neurons, particularly involving the cortex and the striatum. Medium spiny neurons in the striatum that contain $\gamma$ aminobutyric acid and enkephalin are affected early in the disease, and are the primary neurons targeted in HD. These neurons typically project into the lateral globus pallidus. Over time, the degenerative process progresses to involve the remainder of the basal ganglia with subsequent dissemination, including cortex and substantia nigra. Intranuclear and cyoplasmic inclusions of the mhtt aggregate can be demonstrated microscopically. Huntingtin is cross-linked with other soluble $m h t t$ to form the inclusion bodies in neurons. It is not known if the accumulation of $m h t t$ conglomerate results in cell death, or if the soluble form of the protein is the toxic form $[8,9]$. Dopamine, glutamate, and $\gamma$-aminobutyric acid are thought to be the most affected neurotransmitters in HD and are currently the focus of pharmacotherapy (Table 1) [10-23].
Electronic supplementary material The online version of this article (doi:10.1007/s13311-013-0244-z) contains supplementary material, which is available to authorized users.

S. Frank $(\bowtie)$

Boston University School of Medicine, 72 East Concord St, C3, Boston, MA 02118, USA

e-mail: samfrank@bu.edu 
Table 1 Neurotransmitters involved in the pathogenesis of Huntington's disease

\begin{tabular}{lll}
\hline Receptor & Location & Stage of disease \\
\hline Adenosine A2A & Striatum, GPe & Preclinical to advanced \\
Cannabinoid & Striatum, GPe & Preclinical to advanced \\
Dopamine $\mathrm{D}_{1}$ & Striatum, & Clinical diagnosis to advanced \\
& substantia nigra & \\
Dopamine $\mathrm{D}_{2}$ & Caudate, putamen & Prodromal \\
Dynorphin & Striatum & Emergence of dystonia \\
Enkephalin & Striatum & Emergence of chorea \\
GABA & Striatum & Advanced \\
Glutamate & Cortical & Preclinical to advanced \\
Substance P & Striatum & Emergence of dystonia \\
\hline
\end{tabular}

$\mathrm{GPe}=$ globus pallidus externa; $\mathrm{GABA}=\gamma$-aminobutyric acid

There are multiple theories on the pathogenesis of HD. It is likely that more than one process may be occurring at once, but there is evidence to support multiple individual mechanisms, including toxic neuronal aggregates, transcriptional dysregulation, excitotoxicity, mitochondrial dysfunction with altered energy metabolism, and changes in axonal transport and synaptic dysfunction (Table 2) [24-30].

Most European populations show a prevalence rate of 4-8 cases per 100,000 [31-33]. HD is notably rare in Finland and

Table 2 Potential pathways for pathogenesis of Huntington's disease (HD)

\section{Neuronal aggregates}

Neuronal intracytoplasmic and intranuclear inclusions containing mutant huntingtin, truncated $\mathrm{N}$-terminal mutant and wild-type fragment, and chaperones and components of the proteolytic pathway are characteristic of HD neuropathology

Accumulation of mutant protein aggregates may be a result of impairment of the ubiquitin-proteosome pathway

Autophagic mechanisms are implicated in the clearance of protein aggregates

\section{Transcriptional dysregulation}

Aberrant nuclear localization of mutant toxic huntingtin fragments and their association with transcription factors

Dysregulation related to entrapment of transcriptional factors in protein aggregates

Excitotoxicity

Excitotoxic neuron death in HD could result from a combination of increased glutamate and glutamate agonist release from cortical afferents

Mitochondrial dysfunction and altered energy metabolism

Selective inhibitors of complex II of the mitochondrial electron transport chain, 3- nitropropionic acid, and malonate, cause selective striatal neuronal loss similar to that seen in patients with HD

Multitude of bioenergetic defects have been reported in patients with HD

Changes in axonal transport and synaptic dysfunction

Normal huntingtin plays a role in axonal trafficking

Disruption of axonal transport contributes to pathologic process in HD
Japan, but data for Eastern Asia, Africa and Black Americans are inadequate [34]. There are well-known large populations of patients with HD in Scotland and the Lake Maracaibo region of Venezuela $[35,36]$. There have been no widespread epidemiologic studies of HD in the USA since genetic testing became widely available in 1993, but it is estimated that approximately 25,000-30,000 individuals have manifest HD and a further 150,000-250,000 individuals are at risk for HD [37].

Men and women are affected equally, and typically become symptomatic in the third and fourth decades of life. The symptoms of HD can start at any age ranging from 1 to 90 years. Approximately $5-10 \%$ of cases are classified as juvenile onset, with symptoms starting before the age of 20 years. The vast majority of juvenile cases are inherited paternally, and instead of chorea patients may exhibit more parkinsonian signs of bradykinesia, dystonia, tremors, and cognitive deficit [38]. When patients exhibit more hypokinetic features (bradykinesia and dystonia) than hyperkinetic features (chorea), they are said to have the Westphal variant of HD.

HD is diagnosed based on the presence of typical motor findings commonly in the setting of a family history of the disease. There may be other manifestations of HD at the time of presentation or prior to diagnosis based on personality changes or behavioral and cognitive symptoms. A DNA test showing abnormal CAG expansion in the $h t t$ gene can be used to confirm the diagnosis in symptomatic individuals. With proper genetic counseling and at the patient's request, DNA analysis can be performed in individuals at risk for developing HD under the care of experienced clinicians.

The course of the disease is typically $15-20$ years, with dementia, mutism, dystonia, and bradykinesia predominating in advanced disease. Patients with more dystonia and swallowing issues may experience accelerated complications and, therefore, shorter lifespan. Chorea may become a safety issue with larger amplitude movements causing injury or poor positioning. Frequent movements may result in skin injuries, infections, or even fractures and head trauma. Cause of death is typically related to complications of immobility, such as skin breakdown, pneumonia, cardiac disease, or infection. However, $25 \%$ of patients attempt suicide, which is a cause of death in $8-9 \%$ of patients [39].

Behavioral dyscontrol can be a severely disabling symptom of HD causing distress to the patient, family, and caregivers. Environmental approaches and cognitive interventions are the mainstay of treatments, but pharmacological agents can augment addressing disruptive behaviors. Depression, anxiety, aggressive, impulsive, and obsessive-compulsive behaviors are also frequently treated pharmacologically and require behavioral intervention, but caution should be used to avoid oversedation and apathy, already common in patients with HD. Although not well-studied, cognitive approaches to 
treat behavior may be more effective than pharmacotherapy for some aspects of the disease [40]. There have been few clinical trials to examine the effect of agents for cognition in HD such as donepezil, rivastigmine, and atomoxetine. None of the trials to date have demonstrated significant improvement [41-43]. Recent advances in the cognitive aspect of HD have focused on finding improved methods of diagnosing and tracking changes over time [44].

\section{Pharmacological Treatment Options}

Many agents and surgical procedures have been evaluated in HD for their efficacy in suppressing chorea, including dopamine-depleting agents, dopamine antagonists, benzodiazepines, glutamate antagonists, acetylcholinesterase inhibitors, dopamine agonists, antiseizure medications, cannabinoids, lithium, deep brain stimulation, and fetal cell transplantation [45-48]. Pharmacological interventions typically address the hyperkinetic movement disorders that may be associated with HD, such as chorea, dystonia, ballism, myoclonus, and tics. When choosing an intervention, providers should consider if there will be a positive or negative effect of the agent on psychiatric issues associated with $\mathrm{HD}$, such as irritability, depression, anxiety, mania, apathy, obsessive-compulsive disorder, or cognitive decline. Adjunctive therapies, alternative and complementary therapies, behavioral plans, and cognitive interventions also may play a role in addressing the symptoms of HD and need to be considered when choosing medications.

\section{Chorea}

Several reviews have summarized the symptomatic treatment of chorea associated with HD [49-61]. Overall, there is not enough evidence available to guide long-term symptomatic treatment in HD, and double-blind and long-term studies assessing various treatment strategies in HD are needed [55]. Despite the lack of evidence, an American Academy of Neurology Guidelines publication was recently released recommending consideration of tetrabenazine (TBZ), amantadine, or riluzole if chorea requires treatment [46]. A Cochrane review of studies for the symptomatic treatment of HD examined 22 trials that involved 1254 different participants [56]. Nine trials had a crossover design and 13 were conducted in parallel. The studies examined were of relatively short duration, ranging from 2 to 80 weeks. The number of trials examining various pharmacological interventions included antidopaminergic drugs $(n=5)$, glutamate receptor antagonists $(n=5)$, and energy metabolites $(n=5)$. Based on available evidence, the authors of the Cochrane review concluded that only TBZ showed clear efficacy for the control of chorea, but "no statement can be made regarding the best medical practice for the control of motor and non-motor symptoms in HD".

TBZ is the only US Food and Drug Administrationapproved drug for HD, indicated for the treatment of chorea associated with HD. Previous publications have reviewed the chemistry, pharmacodynamics, pharmacokinetics, and mechanism of action [47]. There is a recent review of the development and uses of tetrabenazine [62]. By reversibly inhibiting the central vesicular monoamine transporter type 2, TBZ more selectively depletes dopamine than norepinephrine $[48,63]$. The highest binding density for TBZ is in the caudate nucleus, putamen, and nucleus accumbens, areas known to be most affected in HD [64, 65]. Vesicular monoamine transporter type 2 binding and monoamine depletion by TBZ are reversible, last hours, and are not modified by long-term treatment $[66,67]$.

The efficacy of TBZ as an antichoreic drug was convincingly demonstrated in a double-blind, placebo-controlled trial conducted by the Huntington Study Group [68]. TBZ was titrated weekly in $12.5-\mathrm{mg}$ increments to a maximum of $100 \mathrm{mg} /$ day or to the development of intolerable adverse effects. Compared with baseline, TBZ treatment resulted in a reduction of 5.0 Unified Huntington Disease Rating Scale (UHDRS) total maximal chorea units compared with a reduction of 1.5 units in the placebo group. There is also evidence to suggest continuous long-term efficacy and tolerability of TBZ in patients with HD [69-72].

In the same study, the adverse events that occurred significantly more frequently in the TBZ group included drowsiness or somnolence, insomnia, depressed mood, agitation, akathisia, and hyperkinesia. However, by the conclusion of the maintenance phase, when patients were presumably on optimal dosage, there were no significant differences between TBZ and placebo. Potential side effects include akathisia, depression, dizziness, fatigue, or parkinsonism. During titration, patients may experience insomnia, somnolence, or gastrointestinal distress.

There was one completed suicide in the double-blind study in a subject taking TBZ. Depression is common in HD and can be exacerbated by TBZ. However, attempted or completed suicides in HD do not necessarily correlate with severity of depression, and other associated factors need to be considered, such as impulsiveness, obsessive-compulsive behavior, and socioeconomic factors. Nevertheless, all patients taking TBZ need to be monitored for signs of depression and suicidal ideation. In a follow-on, open-label, extension study, no new adverse effects were reported, and the drug was well tolerated, with an average chronic total daily dose of $62.5 \mathrm{mg}$.

When using TBZ in doses higher than $50 \mathrm{mg} /$ day, the Xenazine product insert states that "patients requiring doses above $50 \mathrm{mg}$ per day should be genotyped for the drug metabolizing enzyme CYP2D6 to determine if the patient is a poor metabolizer or an extensive metabolizer" [73]. 
However, clinically, there is little need to consider genotyping aside from the need for a longer titration in ultra-rapid metabolizers, and there are no distinguishing features of patients with various CYP2D6 genotypes [74].

Other medications that are commonly considered when treating chorea include dopamine antagonists, benzodiazepines, and glutamate antagonists. Dopamine antagonists (neuroleptics) are perhaps the most commonly considered agents in the management of chorea and psychosis in patients with HD, but few double-blind, placebo-controlled studies evaluating the efficacy and safety of these agents have been published [75-77]. None of the typical neuroleptics have been found to be effective in reducing chorea in placebo-controlled trials. However, in a study of haloperidol in 10 patients, oral doses of $1.5-10.0 \mathrm{mg} /$ day corresponded with at least a $30 \%$ reduction in chorea compared with baseline [78]. The quantity and quality of these efficacy data need to be taken into account when considering the risks of using typical neuroleptics, particularly tardive dyskinesia. Apathy and akathisia, other potential adverse effects of the dopamine receptor blockers, can be particularly problematic in patients with HD, as they may not have the insight to recognize these problems or may wrongly attribute the symptoms to HD.

Owing to their presumed improved tolerability, atypical neuroleptics have recently been evaluated in HD. Olanzapine has been used in small open-label studies to treat the motor symptoms of HD [79-83]. The range of effect on chorea has been a reduction of $0-66 \%$. There are no clinical trials of risperidone for $\mathrm{HD}$, but a few reports suggest a positive effect on the disease with a tolerable adverse effect profile [84-87]. Quetiapine has been tried in multiple, small, uncontrolled, nonrandomized trials for HD with some success on both motor and psychiatric symptoms of HD [88-90]. Clozapine was studied in patients with HD up to a dose of $150 \mathrm{mg} /$ day for up to 31 days without benefit and significant adverse events, including drowsiness, fatigue, anticholinergic symptoms, and walking difficulties [91]. The newer atypical agent with multiple mechanisms of action, aripiprazole, has been found to be beneficial in a few small trials with a reduction in chorea equivalent to that with TBZ [92-94]. Although aripiprazole may have fewer adverse effects on mood than TBZ, it may be associated with akathisia and tardive dyskinesia, similar to other typical and atypical neuroleptics.

The N-methyl D-aspartate-antagonist amantadine has been shown in controlled trials to significantly reduce chorea in patients with HD [95]. Doses in the range of $400 \mathrm{mg}$ /day or higher may be required for symptomatic benefit, but even in doses used to treat influenza, amantadine may increase irritability and aggressiveness [96]. Because riluzole retards striatal glutamate release and the pathological consequences in neurotoxic animal models of HD, multiple large trials have been conducted to determine if there is a possible neuroprotective effect. Although there was no clear neuroprotective effect found, riluzole significantly reduced chorea at a dose of $200 \mathrm{mg} /$ day, but not $100 \mathrm{mg} /$ day [97, 98]. Benzodiazepines are also frequently used clinically in patients with HD to treat anxiety and chorea, but there is limited evidence to suggest that higher doses of clonazepam (up to $5.5 \mathrm{mg} /$ day) may be needed to suppress chorea [99]. At this dose, sedation becomes a potential adverse effect. In a few short-term studies (hours), there is evidence that dopamine agonists may reduce the motor signs of HD, vaguely defined as "abnormal involuntary movements" in 2 of the studies and a reduction in the UHDRS total motor score and abnormal involuntary movement scale (AIMS) with apomorphine infusion [100-102]. Although the pharmacological rationale for using dopamine agonists in the treatment of chorea is not clear, presumably they act by activating the presynaptic dopamine receptors leading to decreased dopamine turnover. More likely, however, is that the observed symptomatic effects are related to nonspecific or sedating effects.

The goal of any treatment to reduce chorea should be discussed with the patient and family. Chorea should be reduced to a point that is acceptable to the patient rather than to eliminate chorea completely or to reduce chorea to a level that is acceptable to the caregiver or even physician treating the patient. Because HD is a progressive disease that changes over time, the dose and use of medications need to be reassessed every few months. Considerations when choosing an agent to treat chorea are outlined in Table 3.

\section{Parkinsonism}

For patients with the akinetic form of HD (Westphal variant), antiparkinsonian medications, such as levodopa, dopamine agonists, and amantadine, may be beneficial [103-106]. Botulinum toxin injections can also be considered for focal dystonia associated with $\mathrm{HD}$, both typical presentation

Table 3 Considerations when treating chorea pharmacologically

\begin{tabular}{ll}
\hline $\begin{array}{l}\text { If the patient has } \\
\text { troublesome chorea with: }\end{array}$ & Consider using: \\
\hline $\begin{array}{l}\text { No other symptoms } \\
\text { Weight loss }\end{array}$ & $\begin{array}{l}\text { Tetrabenazine, amantadine, (riluzole) } \\
\text { Olanzapine, cannibinoids }\end{array}$ \\
$\begin{array}{l}\text { Psychosis, aggression } \\
\text { or impulsivity }\end{array}$ & $\begin{array}{c}\text { Aripiprazole, haloperidol, olanzapine, } \\
\text { risperidone, or other neuroleptic }\end{array}$ \\
$\begin{array}{l}\text { Anxiety } \\
\text { Depression }\end{array}$ & $\begin{array}{c}\text { Benzodiazepines } \\
\text { Aripiprazole and avoid tetrabenazine } \\
\text { Apathy }\end{array}$ \\
$\begin{array}{c}\text { Amantadine or stimulating medications } \\
\text { and avoid neuroleptics }\end{array}$ \\
Prominent dystonia & $\begin{array}{c}\text { Amantadine, benzodiazepines, focal } \\
\text { neurotoxin injection, and avoid } \\
\text { neuroleptics }\end{array}$ \\
No response to & Deep brain stimulation \\
pharmacotherapy & \\
\hline
\end{tabular}


and Westphal variant. Even in patients with chorea, underlying dystonia and/or bradykinesia may be present and needs to be addressed.

\section{Behavioral and Psychiatric Disturbance}

There is a wide variety of behavioral and psychiatric issues that may be seen in HD, such as aggression, irritability, impulsiveness, depression, anxiety, apathy, mania, substance abuse, sexual dysfunction, and psychosis. Management outside of pharmacotherapy should be considered when possible, including environmental changes [40]. Although commonly used in HD for depression, anxiety, obsessive-compulsive disorder symptoms and apathy, there is no convincing evidence for the use of selective serotonin reuptake inhibitor, serotonin-norepinephrine reuptake inhibitor, or tricyclic or atypical antidepressant therapies in HD. Similar to other non-motor aspects of HD, treatment recommendations for irritability and obsessive-compulsive behaviors exist only as a paper-based opinion survey $[107,108]$. Until better means of diagnosing cognitive issues in early HD can be established, it will be difficult to develop effective treatments for the cognitive aspect of HD.

\section{Potential New Treatments}

As of 2013, there are a number of ongoing or recently completed studies in HD (http://www.clinicaltrials.gov [109]). However, there continues to be a need for symptomatic agents, and no agent has been proven to change the course of disease. In addition, advanced HD continues to be understudied with a lack of efficacious treatment options. Recently completed studies that showed no to little benefit for cognitive or motor symptoms include latrepirdine (previously called dimebon) and ethyl-eicosapentaenoic acid $[110,111]$. The dopamine-stabilizing agent pridopidine has been studied, and although there was not a statistically significant change in the Modified Motor Score, a subset of the UHDRS Total Motor Score, further studies are underway to determine if the compound may have a positive effect on overall motor function. Pilot studies to evaluate the safety and dosing of memantine and sodium phenylbutyrate have been completed (although not yet published), and larger studies to evaluate safety and efficacy are ongoing.

Currently under study is the compound PBT2, a metal chaperone compound that affects copper interactions with abnormal proteins. PBT2 is a drug designed to interrupt interactions between biological metals and target proteins in the brain, to prevent deterioration of brain cells. It has been shown in animal models, as well as in a small group of patients with Alzheimer's disease, that PBT2 may improve cognition. There is some indication in animal models of HD that the drug may improve motor function and control, and reduce the amount of brain cell degeneration. For symptomatic treatment, a deuterated form of TBZ, SD-809, is being studied to determine if there may be reduced peak dose side effects while delivering improved reduction in chorea.

Although beyond the scope of this review, the key to HD is to find an intervention that will delay onset (motor, cognitive, and other), slow progression, or reverse ongoing disease. To date, there are no effective interventions to do so. However, there are ongoing studies to evaluate supplements that may affect metabolism or mitochondrial function implicated in HD to potentially change the course of disease. The largest include the 5-year study of coenzyme Q10 (2CARE) and the 3-year study of creatine (CREST-E). The green tea extract polyphenon (2)-epigallocatechin-3-gallate is under study for its effect on cognition in patients with HD over a period of 12 months. With the introduction of medical cannabis in some states in the USA, research on this "supplement" should be considered as there is some evidence for cannabinoids in the treatment of chorea and irritability in HD [112].

There are a number of non-pharmacological interventions that are also being more formally evaluated. They may be considered adjunctive to pharmacotherapy, but may, nonetheless, be important as patients and families may have more control, and the interventions are already being used without supporting evidence. In addition, they are generally low-cost, low-risk, and easily accessible in most communities or at home. Some of the interventions include the use of music therapy, exercise, dance, or video game-playing, and most are examining the effect on gait and balance. On the other spectrum of interventions under study is the use of RNA interference to reduce the expression of $m h t t$. RNA interference may be delivered using a viral vector or through direct infusion into the basal ganglia, and both systems are under study, although not yet in humans.

In addition to treating those with manifest disease, if there are means of slowing the progression of disease, then patients who are gene-positive, but not yet manifest, may also benefit with a delay in the onset of disease. Currently, there are safety studies to evaluate the use of coenzyme Q10 (PREQUEL) and creatine (Pre-CREST) in a prodromal or premanifest population. It is likely that other studies will follow if an intervention that slows the progression of disease can be identified.

\section{Conclusion}

Until clear neuroprotective strategies are found, clinicians can address the symptoms of patients with this devastating disease. The most reliable evidence for treating troublesome chorea supports the use of TBZ; however, individual patients may respond to other drugs, and selection should be individualized. The presence of other motor dysfunction, cognitive 
impairment, and behavioral symptoms all need to be considered when choosing therapies for patients. There is also some evidence for the use of riluzole and amantadine. Non-motor issues need to be studied further and treatment options need to be developed. Although there is one Food and Drug Administration-approved option at this time and other medications, hopefully, soon to be available, there are not enough effective, safe interventions that can be offered to our patients and their families at any stage during the course of this illness.

\section{References}

1. The Huntington's Disease Collaborative Research Group. A novel gene containing a trinucleotide repeat that is expanded and unstable on Huntington's disease chromosomes. Cell 1993;72:971-983.

2. Nucifora FC Jr, Sasaki M, Peters MF, et al. Interference by huntingtin and atrophin-1 with cbp-mediated transcription leading to cellular toxicity. Science 2001;291:2423-2428.

3. Subramaniam S, Sixt KM, Barrow R, Snyder SH. Rhes, a striatal specific protein, mediates mutant-huntingtin cytotoxicity. Science 2009;324:1327-1330.

4. Ribeiro FM, Paquet M, Ferreira LT, et al. Metabotropic glutamate receptor-mediated cell signaling pathways are altered in a mouse model of Huntington's disease. J Neurosci 2010;30:316-324.

5. Andrich J, Saft C, Ostholt N, Müller T. Complex movement behavior and progression of Huntington's disease. Neurosci Lett 2007;416:272-274.

6. Frank S, Marshall F, Plumb S, et al. Functional decline due to chorea in Huntington's disease. Neurology 2004;62(Suppl. 5):A204.

7. Verhagen ML, Morris MJ, Farmer C, et al. Huntington's disease: a randomized, controlled trial using the NMDA-antagonist amantadine. Neurology 2002;59:694-699.

8. Bates G. Huntingtin aggregation and toxicity in Huntington's disease. Lancet 2003;361:1642-1644.

9. Arrasate M, Mitra S, Schweitzer ES, Segal MR, Finkbeiner S. Inclusion body formation reduces levels of mutant huntingtin and the risk of neuronal death. Nature 2004;431:805-810.

10. Glass M, Dragunow M, Faull RL. The pattern of neurodegeneration in Huntington's disease: a comparative study of cannabinoid, dopamine, adenosine and $\mathrm{GABA}(\mathrm{A})$ receptor alterations in the human basal ganglia in Huntington's disease. Neuroscience 2000;97:505-519.

11. Albin RL, Reiner A, Anderson KD, et al. Preferential loss of striatoexternal pallidal projection neurons in presymptomatic Huntington's disease. Ann Neurol 1992;31:425-430.

12. Reiner A, Albin RL, Anderson KD, D'Amato CJ, Penney JB, Young AB. Differential loss of striatal projection neurons in Huntington disease. Proc Natl Acad Sci U S A 1988;85:5733-5737.

13. Mitchell IJ, Cooper AJ, Griffiths MR. The selective vulnerability of striatopallidal neurons. Prog Neurobiol 1999;59:691-719.

14. Antonini A, Leenders KL, Spiegel R, et al. Striatal glucose metabolism and dopamine D2 receptor binding in asymptomatic gene carriers and patients with Huntington's disease. Brain 1996;119: 2085-2095.

15. Augood SJ, Faull RL, Emson PC. Dopamine D1 and D2 receptor gene expression in the striatum in Huntington's disease. Ann Neurol 1997;42:215-221.

16. Feigin A, Tang C, Ma Y, et al. Thalamic metabolism and symptom onset in preclinical Huntington's disease. Brain 2007;130:28582867.
17. Andrews TC, Weeks RA, Turjanski N, et al. Huntington's disease progression. PET and clinical observations. Brain 1999;122:23532363.

18. Weeks RA, Piccini P, Harding AE, et al. Striatal D1 and D2 dopamine receptor loss in asymptomatic mutation carriers of Huntington's disease. Ann Neurol 1996;40:49-54.

19. Cha JH, Kosinski CM, Kerner JA, et al. Altered brain neurotransmitter receptors in transgenic mice expressing a portion of an abnormal human huntington disease gene. Proc Natl Acad Sci U S A 1998;95:6480-6485.

20. Perry TL, Hansen S, Kloster M. Huntington's chorea. Deficiency of gamma-aminobutyric acid in brain. N Engl J Med 1973;288:337-342.

21. Paulsen JS. Functional imaging in Huntington's disease. Exp Neurol 2009;216:272-277.

22. Gourfinkel-An I, Parain K, Hartmann A, et al. Changes in GAD67 mRNA expression evidenced by in situ hybridization in the brain of R6/2 transgenic mice. J Neurochem $2003 ; 86: 1369-1378$.

23. Nicniocaill B, Haraldsson B, Hansson O, et al. Altered striatal amino acid neurotransmitter release monitored using microdialysis in R6/1 Huntington transgenic mice. Eur $\mathrm{J}$ Neurosci 2001;13:206-210.

24. Li SH, Li XJ. Huntingtin-protein interactions and the pathogenesis of Huntington's disease. Trends Genet 2004;20:146-154

25. Bence NF, Sampat RM, Kopito RR. Impairment of the ubiquitinproteasome system by protein aggregation. Science 2001;292: 1552-1555.

26. Ravikumar B, Duden R, Rubinsztein DC. Aggregate-prone proteins with polyglutamine and polyalanine expansions are degraded by autophagy. Hum Mol Genet 2002;11:1107-1117.

27. Cha JH. Transcriptional dysregulation in Huntington's disease. Trends Neurosci 2000;23:387-392.

28. Cepeda C, Hurst RS, Calvert CR, et al. Transient and progressive electrophysiological alterations in the corticostriatal pathway in a mouse model of Huntington's disease. J Neurosci 2003;23:961-969.

29. Ludolph AC, He F, Spencer PS, Hammerstad J, Sabri M. 3Nitropropionic acid-exogenous animal neurotoxin and possible human striatal toxin. Can J Neurol Sci 1991;18:492-498.

30. Gunawardena S, Goldstein LS. Polyglutamine diseases and transport problems: deadly traffic jams on neuronal highways. Arch Neurol 2005;62:46-51.

31. Harper PS. The epidemiology of Huntington's disease. Hum Genet 1992;89:365-376.

32. Morrison PJ, Johnston WP, Nevin NC. The epidemiology of Huntington's disease in Northern Ireland. J Med Genet 1995;32: 524-530.

33. Peterlin B, Kobal J, Teran N, et al. Epidemiology of Huntington's disease in Slovenia. Acta Neurol Scand 2009;119:371-375.

34. Alonso ME, Ochoa A, Boll MC, et al. Clinical and genetic characteristics of Mexican Huntington's disease patients. Mov Disord 2009;24:2012-2015.

35. Simpson SA, Johnston AW. The prevalence and patterns of care of Huntington's chorea in Grampian. Br J Psychiatry 1989;155:799-804.

36. Penney JB Jr, Young AB, Shoulson I, et al. Huntington's disease in Venezuela: 7 years of follow-up on symptomatic and asymptomatic individuals. Mov Disord 1990;5:93-99.

37. Harper PS. The epidemiology of Huntington's disease. In: Bates G, Harper P, Jones L, eds. Huntington's disease. 3rd ed. Oxford Monographs on Medical Genetics, 2002.

38. Ribai P, Nguyen K, Hahn-Barma V, et al. Psychiatric and cognitive difficulties as indicators of juvenile huntington disease onset in 29 patients. Arch Neurol 2007;64:813-819.

39. Di ML, Squitieri F, Napolitano G, Campanella G, Trofatter JA, Conneally PM. Suicide risk in Huntington's disease. J Med Genet 1993;30:293-295. 
40. Pollard J. Hurry up and wait: a cognitive care companion. 9/25/08. XX, Lulu Press, US, 2008. http://www.lulu.com/shop/james-pollard/ hurry-up-and-wait/paperback/product-3610588.html\#productDetails

41. Cubo E, Shannon KM, Tracy D, et al. Effect of donepezil on motor and cognitive function in Huntington disease. Neurology 2006;67: $1268-1271$.

42. de Tommaso M, Difruscolo O, Sciruicchio V, Specchio N, Livrea P. Two years' follow-up of rivastigmine treatment in Huntington disease. Clin Neuropharmacol 2007;30:43-46.

43. Beglinger LJ, Adams WH, Paulson H, et al. Randomized controlled trial of atomoxetine for cognitive dysfunction in early Huntington disease. J Clin Psychopharmacol 2009;29:484-487.

44. Paulsen Cognitive impairment in Huntington disease: diagnosis and treatment. Curr Neurol Neurosci Rep 2011;11:474-483.

45. Pidgeon C, Rickards $\mathrm{H}$. The pathophysiology and pharmacological treatment of Huntington disease. Behav Neurol 2013;26:245-253.

46. Armstrong MJ, Miyasaki JM; American Academy of Neurology. Evidence-based guideline: pharmacologic treatment of chorea in Huntington disease: report of the guideline development subcommittee of the American Academy of Neurology. Neurology 2012;79:597-603.

47. Paleacu D. Tetrabenazine in the treatment of Huntington's Disease. Neuropsychiatr Dis Treat 2007;3:545-551.

48. Bagchi SP. Differential interactions of phencyclidine with tetrabenazine and reserpine affecting intraneuronal dopamine. Biochem Pharmacol 1983;32:2851-2856.

49. Adam OR, Jankovic J. Symptomatic treatment of Huntington disease. Neurotherapeutics 2008;5:181-197.

50. Phillips W, Shannon KM, Barker RA. The current clinical management of Huntington's disease. Mov Disord 2008;23:1491-1504.

51. Roze E, Saudou F, Caboche J. Pathophysiology of Huntington's disease: from huntingtin functions to potential treatments. Curr Opin Neurol 2008;21:497-503.

52. Imarisio S, Carmichael J, Korolchuk V, et al. Huntington's disease: from pathology and genetics to potential therapies. Biochem J 2008;412:191-209.

53. Walker FO. Huntington's disease. Lancet 2007;369:218-228.

54. Jankovic J. Treatment of hyperkinetic movement disorders. Lancet Neurol 2009;8:844-856.

55. Bonelli RM, Wenning GK. Pharmacological management of Huntington's disease: an evidence-based review. Curr Pharm Des 2006;12:2701-2720.

56. Mestre T, Ferreira J, Coelho MM, Rosa M, Sampaio C. Therapeutic interventions for symptomatic treatment in Huntington's disease. Cochrane Database Sys Rev 2009:CD006456.

57. Nakamura K, Aminoff MJ. Huntington's disease: clinical characteristics, pathogenesis and therapies. Drugs Today (Barc) 2007;43:97-116.

58. Handley OJ, Naji JJ, Dunnett SB, Rosser AE. Pharmaceutical, cellular and genetic therapies for Huntington's disease. Clin Sci (Lond) 2006;110:73-88.

59. Bonelli RM, Hofmann P. A review of the treatment options for Huntington's disease. Expert Opin Pharmacother 2004;5:767-776.

60. Grimbergen YA, Roos RA. Therapeutic options for Huntington's disease. Curr Opin Investig Drugs 2003;4:51-54.

61. Frank SA, Jankovic J. Advances in the pharmacological management of Huntington's Disease. Drugs 2010;70:561-571.

62. Jankovic J, Clarence-Smith K. Tetrabenazine for the treatment of chorea and other hyperkinetic movement disorders. Expert Rev Neurother 2011;11:1509-1523.

63. Pettibone DJ, Pflueger AB, Totaro JA. Tetrabenazine-induced depletion of brain monoamines: mechanism by which desmethylimipramine protects cortical norepinephrine. Eur J Pharmacol 1984;102:431-436.

64. Mehvar R, Jamali F. Concentration-effect relationships of tetrabenazine and dihydrotetrabenazine in the rat. J Pharm Sci 1987;76:461-465.
65. Thibaut F, Faucheux BA, Marquez J, et al. Regional distribution of monoamine vesicular uptake sites in the mesencephalon of control subjects and patients with Parkinson's disease: a postmortem study using tritiated tetrabenazine. Brain Res 1995;692:233-243.

66. Kenney C, Hunter C, Davidson A, Jankovic J. Short-term effects of tetrabenazine on chorea associated with Huntington's disease. Mov Disord 2007;22:10-13.

67. Scherman D, Henry JP. Reserpine binding to bovine chromaffin granule membranes. Characterization and comparison with dihydrotetrabenazine binding. Mol Pharmacol 1984;25:113-122.

68. Huntington Study Group. Tetrabenazine as antichorea therapy in Huntington disease: a randomized controlled trial. Neurology 2006; 66:366-372.

69. Jankovic J, Beach J. Long-term effects of tetrabenazine in hyperkinetic movement disorders. Neurology 1997;48:358-362.

70. Kenney C, Hunter C, Jankovic J. Long-term tolerability of tetrabenazine in the treatment of hyperkinetic movement disorders. Mov Disord 2007;22:193-197.

71. Fasano A, Cadeddu F, Guidubaldi A, et al. The long-term effect of tetrabenazine in the management of Huntington disease. Clin Neuropharmacol 2008;31:313-318.

72. Frank S. Tetrabenazine as anti-chorea therapy in Huntington disease: an open-label continuation study. Huntington Study Group/ TETRA-HD Investigators. BMC Neurol 2009;9:62.

73. Xenazine. Product information, September 2012. http://www. lundbeck.com/upload/us/files/pdf/Products/Xenazine_PI_US_EN.pdf

74. Mehanna R, Hunter C, Davidson A, Jimenez-Shahed J, Jankovic J. Analysis of CYP2D6 genotype and response to tetrabenazine. Mov Disord 2013;28:210-215.

75. Quinn N, Marsden CD. A double blind trial of sulpiride in Huntington's disease and tardive dyskinesia. J Neurol Neurosurg Psychiatry 1984;47:844-847.

76. Deroover J, Baro F, Bourguignon RP, Smets P. Tiapride versus placebo: a double-blind comparative study in the management of Huntington's chorea. Curr Med Res Opin 1984;9:329-338.

77. Leonard DP, Kidson MA, Brown JG, Shannon PJ, Taryan S. A double blind trial of lithium carbonate and haloperidol in Huntington's chorea. Aust N Z J Psychiatry 1975;9:115-118.

78. Barr AN, Fischer JH, Koller WC, Spunt AL, Singhal A. Serum haloperidol concentration and choreiform movements in Huntington's disease. Neurology 1988;38:84-88.

79. Bonelli RM, Mahnert FA, Niederwieser G. Olanzapine for Huntington's disease: an open label study. Clin Neuropharmacol 2002;25:263-265.

80. Bonelli RM, Niederwieser G, Tribl GG, Költringer P. High-dose olanzapine in Huntington's disease. Int Clin Psychopharmacol 2002;17:91-93.

81. Paleacu D, Anca M, Giladi N. Olanzapine in Huntington's disease. Acta Neurol Scand 2002;105:441-444.

82. Squitieri F, Cannella M, Piorcellini A, Brusa L, Simonelli M, Ruggieri S. Short-term effects of olanzapine in Huntington disease. Neuropsychiatry Neuropsychol Behav Neurol 2001;14:69-72.

83. Dipple HC. The use of olanzapine for movement disorder in Huntington's disease: a first case report. J Neurol Neurosurg Psychiatry 1999;67:123-124.

84. Cankurtaran ES, Ozalp E, Soygur H, Cakir A. Clinical experience with risperidone and memantine in the treatment of Huntington's disease. J Natl Med Assoc. 2006;98:1353-1355.

85. Erdemoglu AK, Boratav C. Risperidone in chorea and psychosis of Huntington's disease. Eur J Neurol 2002;9:182-183.

86. Madhusoodanan S, Brenner R. Use of risperidone in psychosis associated with Huntington's disease. Am J Geriatr Psychiatry 1998;6:347-349.

87. Parsa MA, Szigethy E, Voci JM, Meltzer HY. Risperidone in treatment of choreoathetosis of Huntington's disease. J Clin Psychopharmacol 1997;17:134-135. 
88. Alpay M, Koroshetz WJ. Quetiapine in the treatment of behavioral disturbances in patients with Huntington's disease. Psychosomatics 2006;47:70-72.

89. Seitz DP, Millson RC. Quetiapine in the management of psychosis secondary to Huntington's disease: a case report. Can J Psychiatry 2004;49:413.

90. Bonelli RM, Niederwieser G. Quetiapine in Huntington's disease: a first case report. J Neurol 2002;249:1114-1115.

91. van Vugt JP, Siesling S, Vergeer M, van der Velde EA, Roos RA. Clozapine versus placebo in Huntington's disease: a double blind randomised comparative study. J Neurol Neurosurg Psychiatry 1997;63:35-39.

92. Ciammola A, Sassone J, Colciago C, et al. Aripiprazole in the treatment of Huntington's disease: a case series. Neuropsychiatr Dis Treat 2009;5:1-4.

93. Brusa L, Orlacchio A, Moschella V, Iani C, Bernardi G, Mercuri NB. Treatment of the symptoms of Huntington's disease: preliminary results comparing aripiprazole and tetrabenazine. Mov Disord 2009;24:126-129.

94. Lin WC, Chou YH. Aripiprazole effects on psychosis and chorea in a patient with Huntington's disease. Am J Psychiatry 2008;165: $1207-1208$.

95. Lucetti C, Gambaccini G, Bernardini S, et al. Amantadine in Huntington's disease: open-label video-blinded study. Neurol Sci 2002;23(Suppl. 2):S83-S84.

96. Stewart JT. Adverse behavioral effects of amantadine therapy in Huntington's disease. South Med J 1987;80:1324-1325.

97. Huntington Study Group. Dosage effects of riluzole in Huntington's disease: a multicenter placebo-controlled study. Neurology 2003;61:1551-1556.

98. Landwehrmeyer GB, Dubois B, de Yebenes JG, et al. Riluzole in Huntington's disease: a 3-year, randomized controlled study. Ann Neurol 2007;62:262-272.

99. Peiris JB, Boralessa H, Lionel ND. Clonazepam in the treatment of choreiform activity. Med J Aust 1976;1:225-227.

100. Frattola L, Albizzati MG, Alemani A, Bassi S, Ferrarese C, Trabucchi M. Acute treatment of Huntington's chorea with lisuride. J Neurol Sci 1983;59:247-253.
101. Vitale C, Marconi S, Di ML, et al. Short-term continuous infusion of apomorphine hydrochloride for treatment of Huntington's chorea: a double blind, randomized cross-over trial. Mov Disord 2007;22: 2359-2364.

102. Corsini GU, Onali P, Masala C, Cianchetti C, Mangoni A, Gessa G. Apomorphine hydrochloride-induced improvement in Huntington's chorea: stimulation of dopamine receptor. Arch Neurol 1978;35:27-30.

103. Low PA, Allsop JL, Halmagyi GM. Huntington's chorea: the rigid form (Westphal variant) treated with levodopa. Med J Aust 1974;1: 393-394.

104. Low PA, Allsop JL. Huntington's chorea - the rigid form (Westphal variant) treated with 1-DOPA: a case report. Proc Aust Assoc Neurol 1973;10:45-46.

105. Magnet MK, Bonelli RM, Kapfhammer HP. Amantadine in the akinetic-rigid variant of Huntington's disease. Ann Pharmacother 2004;38:1194-1196.

106. Bonelli RM, Niederwieser G, Diez J, Gruber A, Költringer P. Pramipexole ameliorates neurologic and psychiatric symptoms in a Westphal variant of Huntington's disease. Clin Neuropharmacol 2002;25:58-60.

107. Groves M, van Duijn E, Anderson K, et al. An international surveybased algorithm for the pharmacologic treatment of irritability in Huntington's disease. PLoS Curr 2011;30:3.

108. Anderson K, Craufurd D, Edmondson MC, et al. An international survey-based algorithm for the pharmacologic treatment of obsessive-compulsive behaviors in Huntington's disease. PLoS Curr 2011;20:3

109. www.clinicaltrials.gov. Accessed August 9, 2013.

110. Kieburtz K, McDermott MP, Voss TS, et al. A randomized, placebocontrolled trial of latrepirdine in Huntington disease. Arch Neurol 2010;67:154-160.

111. Huntington Study Group TREND-HD Investigators. Randomized controlled trial of ethyl-eicosapentaenoic acid in Huntington disease: the TREND-HD study. Arch Neurol 2008;65:1582-1589.

112. Curtis A, Rickards H. Nabilone could treat chorea and irritability in Huntington's disease. J Neuropsychiatry Clin Neurosci 2006;18: $553-554$. 